Research Article

Araştırma Makalesi

DOI: $10.24011 /$ barofd.519207
Bartın Orman Fakultesi Dergisi,

21 (1): 136-146

15 Nisan/April, 2019
Journal of Bartin Faculty of Forestry

p-ISSN :1302-0943

e-ISSN :1308-5875

\title{
Orman Ürünleri İşletmelerinin Finansal Performanslarının Entropi Temelli TOPSIS Yöntemi ile Karşılaştırılması: Artvin Örneği
}

\author{
İlker AKYÜZ1* ${ }^{*}$, Barış AYDEMİ², Bahadır Çağrı BAYRAM³ ${ }^{3}$, Kadri Cemil AKYÜZ1 \\ ${ }^{1}$ Karadeniz Teknik Üniversitesi, Orman Fakültesi, Orman Endüstri Mühendisliği Bölümü, 61100, TRABZON \\ ${ }^{2}$ Artvin Çoruh Üniversitesi, Artvin Meslek Yüksekokulu, Bankacılık ve Finans Bölümü, 08000, ARTVİN \\ ${ }^{3}$ Kastamonu Üniversitesi, Orman Fakültesi, Orman Endüstri Mühendisliği Bölümü, 37100, KASTAMONU
}

\section{Öz}

Bu çalışmada, Artvin ilinde faaliyet gösteren orman ürünleri işletmelerinin finansal performansları TOPSIS yöntemi kullanılarak değerlendirilmiş ve karşılaştırılmıştır. Bu çalışma kapsamına 6 adet işletme alınmıştır ve finansal performanslarının belirlenmesi için 2014-2017 yıllarına ait veriler kullanılmıştır. Çalışmada 11 adet finansal oran (kriter) kullanılmış olup, bu kriterler mali tablolar yardımıyla hesaplanmıştır. İlk olarak Entropi yöntemi kullanılarak kriterlerin ağırlıkları belirlenmiş ve daha sonra Technique for Order Preference by Similarity to Ideal Solution (TOPSIS) yöntemi ile işletmelerin performansları sıralanmıştır. Kriterlerin ağırlıkları bakımından 2014, 2015 ve 2017 yılları için özkaynak devir hızı kriterinin ve 2016 yılı için asit-test oranı kriterinin daha önemli olduğu bulunmuştur. İşletmelerin finansal performansları değerlendirildiğinde ise genel olarak "E" işletmesinin en iyi finansal performans sergilediği, en kötü finansal performans sergileyen işletmelerin yıllara göre farkl1lık gösterdiği bulunmuştur.

Anahtar Kelimeler: Orman ürünleri, finansal performans, entropi, TOPSIS.

\section{The Comparison of Financial Performance of the Forest Products Enterprises Using the Entropy-Based TOPSIS Method: A Case of Artvin}

\begin{abstract}
In this study, the financial performances of forest products enterprises operating in Artvin province were evaluated and compared using Technique for Order Preference by Similarity to Ideal Solution (TOPSIS) method. Six enterprises were included in the scope of this study and the data in 2014-2017 were used to determine their financial performance. In this paper were used 11 financial ratios obtained from the balance sheet and income statements. First, the weights of the criteria were determined by using the entropy method and then, the performances of the enterprises were ranked by TOPSIS method. In terms of weights of the criteria, it was found that the criteria of the equity turnover rate for 2014, 2015 and 2017 and the acid-test rate for 2016 are more important. When we evaluate the financial performances of the enterprises, it was found that the "E" enterprise has the best financial performance and the enterprises, which have the worst performance, varied from year to year.
\end{abstract}

Keywords: Forest products, financial performance, entropy, TOPSIS. 


\section{Giriş}

Türkiye'de genel imalat sanayinin \%25'lik k1smını oluşturan orman ürünleri sanayisi birincil ve ikincil imalat sanayi grupları olarak tanımlanmaktadır. Birincil imalat sanayi grubunu kereste ve ambalaj sanayisi, levha sanayisi ve kağıt hamuru ve kağıt sanayisi oluşturmaktadır. İkincil imalat sanayi grubunu ise mobilya, doğrama, ahşap parke, prefabrik ev gibi sanayiler oluşturmaktadır. Orman ürünleri sanayisi çok sayıda sanayi koluna hammadde sağlamakta ve yaklaşık 300.000 kişiye istihdam olanağı vermektedir. Türkiye'deki ekonomik yeri açısından incelediğinde ise 2018 yılı Ocak ayı sektörel bazda ihracat rakamlarına göre orman ürünleri sanayisinin ihracatı, Türkiye'deki toplam ihracatının \%3'ünü oluşturmaktadır (Akyüz, 2006; Şahin, 2016; Cantürk, 2018; Ersen ve ark. 2018).

Her sanayide olduğu gibi orman ürünleri sanayisinde de faaliyet gösteren işletmelerinin karlarını artırmak, satışlarını maksimum seviyeye çıkarmak ve rekabet ortamında ayakta kalabilmek için sağlıklı ve zamanında kararlar almaları gerekmektedir.

Çok Kriterli Karar Verme (ÇKKV) teknikleri yardımı ile karar vericiler etkin ve kolay kararlar verebilirler. ÇKKV teknikleri birbirinden bağımsız ve farklı şekillerde ifade edilen faktörleri dikkate alarak analiz yapması sonucunda elde ettikleri sonuçlar yardımı ile alternatifleri sınırlayan ve alternatifler arasından seçme ve sınıflandırma yapan tekniklerdir (Urfalıoğlu ve Genç, 2013; Akyüz ve ark. 2017). Literatürde farklı ÇKKV teknikleri bulunmakta olup, bu çalışmada ÇKKV tekniklerinden biri olan Technique for Order Preference by Similarity to Ideal Solution (TOPSIS) yöntemi kullanılarak Artvin ilindeki orman ürünleri işletmelerinin finansal performanslarının karşılaştırılması yapılmıştır. Kriterlerin ağırlık değerleri ise entropi yöntemi yardımı ile belirlenmiştir. İşletmelerin finansal performanslarının TOPSIS yöntemi, Entropi temelli TOPSIS yöntemi kullanılarak ölçülmesi ile ilgili çalışmalar bulunmakta olup, bu çalışmalardan bazıları Tablo 1'de kısaca özetlenmiştir.

Tablo 1. Technique for Order Preference by Similarity to Ideal Solution (TOPSIS) ve Entropi temelli TOPSIS yöntemleri kullanılarak finansal performans değerlendirmesi yapılmış çalışmalar

\begin{tabular}{|c|c|c|}
\hline Yazarlar & Çalışmanın yapıldığı sektör & Yöntem \\
\hline Feng ve Wang (2000) & Tayvan'daki havayolu şirketleri & TOPSIS \\
\hline Deng ve ark. (2000) & $\begin{array}{l}\text { Çin'de faaliyet gösteren tekstil } \\
\text { işletmeleri }\end{array}$ & Entropi-TOPSIS \\
\hline Wang ve Hsu (2004) & $\begin{array}{l}\text { Tayvan Borsasında işlem gören } \\
\text { bilgisayar üretimi yapan işletmeler }\end{array}$ & Entropi-TOPSIS \\
\hline Dai ve Wang (2011) & $\begin{array}{l}\text { Şangay ve Shenzhen Menkul } \\
\text { Kiymetler Borsası'nda işlem gören } \\
\text { elektrik şirketleri }\end{array}$ & Entropi-TOPSIS \\
\hline Y1lmaz ve Konyar (2013) & $\begin{array}{l}\text { İstanbul Borsa'sında işlem gören } \\
\text { halka açık konut şirketleri }\end{array}$ & TOPSIS \\
\hline Bulgurcu (2013) & $\begin{array}{l}\text { İstanbul Borsa'sında işlem gören } \\
\text { otomotiv işletmeleri }\end{array}$ & Entropi-TOPSIS \\
\hline Özçelik ve Kandemir (2015) & $\begin{array}{l}\text { BIST'te işlem gören turizm } \\
\text { ișletmeleri }\end{array}$ & TOPSIS \\
\hline İslamoğlu ve ark. (2015) & $\begin{array}{l}\text { İstanbul Borsa'sında gayrimenkul } \\
\text { yatırım fonu işletmeleri }\end{array}$ & Entropi-TOPSIS \\
\hline Y1lmaz ve ark. (2016) & $\begin{array}{l}\text { BIST'te işlem gören gida maddeleri } \\
\text { sanayi işletmeleri }\end{array}$ & TOPSIS \\
\hline Şit ve ark. (2017) & $\begin{array}{l}\text { BIST'te isslem gören ana metal sanayi } \\
\text { işletmesi }\end{array}$ & TOPSIS \\
\hline Temür ve ark. (2017) & $\begin{array}{l}\text { BIST'te işlem gören perakende } \\
\text { ticaret işletmeleri }\end{array}$ & TOPSIS \\
\hline Kayıhan (2017) & $\begin{array}{l}\text { BIST'te faaliyet gösteren taş ve } \\
\text { toprağa dayalı işletmeler }\end{array}$ & TOPSIS \\
\hline Üçüncü ve ark. (2017a) & Ahşap panel endüstrisi & TOPSIS \\
\hline Üçüncü ve ark. (2017b) & $\begin{array}{l}\text { Mobilya endüstrisinde kuruluş yeri } \\
\text { seçimi }\end{array}$ & TOPSIS \\
\hline Kayalı ve Aktaş (2018) & $\begin{array}{l}\text { BIST'te işlem gören otomotiv } \\
\text { işletmeleri }\end{array}$ & TOPSIS \\
\hline Üçüncü ve ark. (2018) & BIST'te işlem gören kağıt işletmeleri & TOPSIS \\
\hline Perçin ve Sönmez (2018) & $\begin{array}{l}\text { Borsa İstanbul'da işlem gören sigorta } \\
\text { işletmeleri }\end{array}$ & Entropi-TOPSIS \\
\hline
\end{tabular}




\section{Materyal ve Metot}

\subsection{Materyal}

Bu çalışmanın materyalini Artvin'de orman ürünleri sanayisinde faaliyet gösteren 6 işletmenin 2014-2017 dönemlerine ait bilanço ve gelir tabloları kullanılarak elde edilen 11 adet finansal oran oluşturmaktadır. Çalışmada kullanılan finansal oranların hesaplanmasında işletmelerden alınan mali tablolar kullanılmıştır. Ayrıca, analiz sırasında ve sonuç bölümünde firmaların isimleri farklı algılara neden olmaması için gizlenmiş ve farklı ifadelerle tanımlanmışlardır. Finansal performansları değerlendirilen işletmeler Tablo 2'de ve çalışmada kullanılan finansal oranlar Tablo 3'te gösterilmiştir.

Tablo 2. Çalışmada kullanılan işletmeler

\begin{tabular}{l}
\hline \multicolumn{1}{c}{ İşletmeler } \\
\hline Engin Akdemir Şahıs Şirketi \\
Fatih Terbıyık Şahıs Şirketi \\
Güvenler Doğ. İml. İnş. Mob. San. Tur. Nak. Tic. Ltd. Şti. \\
Ormanlı Orman Ürünleri İma.İnş Taah. İth .İhr. Ltd. Şti. \\
Sait Güreli Şahıs Şirketi \\
Borçkalılar Nakliyat Trz.Taah. İnşaat Tic. Ltd.Şti \\
\hline
\end{tabular}

Tablo 3. Analizde kullanılan finansal oranlar

\begin{tabular}{|c|c|c|c|}
\hline \multicolumn{2}{|r|}{ Oranlar } & Formül & Kodlar \\
\hline \multirow{2}{*}{$\begin{array}{l}\text { Likidite } \\
\text { oranlar1 }\end{array}$} & Cari oran & $\begin{array}{l}\text { Dönen varlıklar / Kisa vadeli yabancı } \\
\text { kaynaklar }\end{array}$ & L1 \\
\hline & Asit-test oranı & $\begin{array}{c}\text { (Dönen varlıklar - Stoklar) / Kısa } \\
\text { vadeli yabancı kaynaklar }\end{array}$ & L2 \\
\hline \multirow{3}{*}{$\begin{array}{c}\text { Mali yap1 } \\
\text { oranları }\end{array}$} & Kaldıraç oranı & $\begin{array}{c}\text { Toplam yabancı kaynaklar / Toplam } \\
\text { pasifler }\end{array}$ & M1 \\
\hline & Finansman oranı & Özkaynak / Toplam yabancı kaynaklar & M2 \\
\hline & $\begin{array}{l}\text { Duran varlıkların devamlı sermayeye } \\
\text { oranı }\end{array}$ & $\begin{array}{c}\text { Duran varlıklar / (Uzun vadeli yabancı } \\
\text { kaynaklar + Özkaynak) }\end{array}$ & M3 \\
\hline \multirow{2}{*}{$\begin{array}{l}\text { Faaliyet } \\
\text { oranları }\end{array}$} & Özkaynak devir hızı & Net satışlar / Özkaynak & $\mathrm{F} 1$ \\
\hline & Aktif devir hızı & Net satışlar / Toplam varlıklar & F2 \\
\hline \multirow{4}{*}{$\begin{array}{l}\text { Karlılık } \\
\text { oranları }\end{array}$} & Net kar marj1 & Net Kar/ Net satışlar & $\mathrm{K} 1$ \\
\hline & Özkaynak karlılı̆̆ 1 & Net kar / Özkaynak & $\mathrm{K} 2$ \\
\hline & Aktif karlılı̆̆ 1 & Net Kar / Toplam varlıklar & $\mathrm{K} 3$ \\
\hline & Maliyet / Net satışlar & Maliyet / Net satışlar & $\mathrm{N} 1$ \\
\hline
\end{tabular}

Likidite oranlar, işletmelerinin kısa vadeli borçlarını ödeme gücünü ölçmek ve işletme sermayesinin yeterli olup olmadığını belirlemek için kullanılmaktadır. Likidite oranlarının değerlendirilmesinde sektörel farklılıklar göz önünde bulundurulmalıdır. Çalışmada likidite oranlarından cari oran ve asit-test oranı kullanılmıştır. Cari oran, işletmelerin likidite durumunu göstererek işletme sermayesinin yeterli olup olmadığını belirlediği için "İşletme Sermayesi Oranı" olarak adlandırıldığı gibi bu oran bankalar tarafindan kredi taleplerinin değerlendirilmesinde kullanıldığı için “Banker Oranı” olarak da adlandırılmaktadır. Cari oranın 1-2 arasında veya 2'den büyük olması istenmektedir (Karademir, 2016). Çalışmada kullanılan asit-test oranı ise cari oranı tamamlayan bir orandır. Bu oranın genelde 1 olması istenmektedir (Savc1, 2013).

Faaliyet oranları yardımıyla da işletme faaliyetlerinde kullanılan varlıkların etkili bir şekilde kullanılıp kullanılmadığı tespit edilmektedir (Özerol, 2015). Çalışmada faaliyet oranlarından özkaynak devir hızı ve aktif devir hızı kullanılmıştır. Özkaynak devir hızı özkaynakların etkin kullanılıp kullanılmadığını gösterirken, aktif devir hızı ise aktiflerin etkin kullanılıp kullanılmadığını gösterir. Aktif devir hızının yüksek olması işletmenin kapasiteyi verimli bir şekilde kullandığını ifade etmektedir (Savcı, 2013).

Mali yapı oranları ise işletmelerin yabancı kaynakları ile öz kaynakları arasındaki ilişkiyi göstermektedir (Özerol, 2015). Çalışmada mali yapı oranlarından kaldıraç oranı, finansman oranı ve duran varlıkların devamlı sermayeye oranı kullanılmıştır. Borçlanma oranı olarak da adlandırılan kaldıraç oranının düşük olması tercih edilmektedir. Çünkü bu oranın artması işletmenin katlandığı riskleri arttıracaktır. Finansman oranı işletmenin mali açıdan bağımsızlık seviyesini gösteren oran olup, oranın en az 1 olması öngörülmektedir. Duran varlıkların 
devamlı sermayeye oranı ise işletmelerin maddi yatırımlarının fonlamada hangi oranda başarılı olduğunu göstermekte olup, bu oranın 1'den düşük olması istenmektedir (Özerol, 2015; Karademir, 2016).

Son olarak karlılık oranları da işletmelerin elde ettiği karın yeterli olup olmadığını analiz etmektedir (Karademir, 2016). Bu oranların yeterli olup olmadığı belirlenirken; alternatif yatırım alanları işletmenin kar beklentisi ekonomik şartlar ve benzer işletmelerin karlılık oranları da dikkate alınmalıdır (Savc1, 2013). Çalışmada karlılık oranlarından net kar marjı, özkaynak karlılığı ve aktif karlılığı kullanılmıştır. İşletmenin etkin bir maliyet kontrolünün olup olmadığını ölçen kar marjının yüksek olması istenmektedir. Çünkü bu oranın yüksek oluşu işletmenin kredi geri ödeme gücünün ve firmanın devamlılığını göstermektedir. Aktif karlılığ1 oranı işletmenin az sermaye ile başarılı olup olmadığını değerlendiren bir orandır (Özerol, 2015; Karademir, 2016). Özkaynak karlılığı ise işletmeye sermaye koyanlara ait bir başarı ölçüsüdür. Bu oran net kar marjı, aktif devir hızı ve finansman kaldıraç oranı yardımıyla belirlenmektedir (Savcı, 2013).

\subsection{Entropi Yöntemi}

Ağırlık hesaplama için en çok kullanılan yöntemlerden biri olan Entropi kavramı, Shannon ve Weaver (1949) tarafından önerilmiş ve olasılık teorisi kullanılarak formüle edilmiş olan enformasyondaki belirsizlik ölçüsü olarak tanımlanmaktadır (Deng ve ark. 2000; Shemshadi ve ark. 2011). Entropi yönteminin adımları aşağıdaki gibi sıralanmıştır (Wang ve Hsu, 2004; Wang ve Lee, 2009; Woo Lee ve ark. 2012; Chen, ve ark. 2015).

Adım 1: Karar matrisinin oluşturulması

Karar matrisi alternatifler ve değerlendirme kriterlerinden oluşmakta olup, karar matrisin satırlar kısmında alternatifler, sütunlar kısmında değerlendirme kriterleri yer almaktadır. Karar matrisi aşağıdaki gibidir:

$X=\left|\begin{array}{ccc}x_{11} & \ldots & x_{1 n} \\ \ldots & \ldots & \ldots \\ x_{m 1} & \ldots & x_{m n}\end{array}\right|$

Adım 2: Normalizasyon işlemi

Her bir alternatifin aldığı kriter değeri her bir alternatif değerinin karelerinin toplamına bölünerek normalizasyon işlemi yapılmaktadır. Bunun için aşağıdaki denklem kullanılmaktadır:

$$
x_{i j}^{g}=\frac{x_{i j}}{\sum_{i=1}^{i n} x_{i j}}
$$

Adım 3: Entropi değerinin hesaplanması

Normalizasyon işleminden sonra, denklem (2) kullanılarak her bir kritere ait entropi değeri hesaplanır. Denklemdeki, "k" entropi katsayısını ifade etmektedir. "k" değeri toplam alternatif sayısının In'inin tersidir. "ej” ise entropi değeridir. "ej” değeri 0 ile 1 arasında bir değer almaktadır.

$$
\begin{gathered}
e_{j}=-k \sum_{j=1}^{n} x_{i j}^{s} \ln x_{i j}^{s} \\
k=(\ln (n))^{-1}
\end{gathered}
$$

Adım 4: Ağırlık değerinin hesaplanması

Denklem (3) kullanılarak her bir kritere ait ağırlık değeri hesaplanır. Ağırlık değerleri hesaplanırken her bir kriterin entropi değeri kullanılmaktadır. Her bir kriter için hesaplanan ağırlık değerlerinin toplamı 1 olmalıdır $\left(\sum_{1}^{m} w_{j}=1\right)$. Ağırlık değeri " $w_{j}$ ” ile gösterilmektedir.

$$
w_{j}=\frac{1-e_{j}}{\Sigma_{1}^{1}\left(1-e_{j}\right)}
$$

\subsection{Technique for Order Preference by Similarity to Ideal Solution (TOPSIS) Yöntemi}

Technique for Order Preference by Similarity to Ideal Solution (TOPSIS) yöntemi ilk olarak Hwang ve Yoon (1981) tarafından önerilmiş, daha sonra da Yoon (1987) ve Hwang ve arkadaşları (1993) tarafindan geliştirilmiştir. TOPSIS yönteminin temel prensibi, pozitif ideal çözüme en yakın ve negatif ideal çözüme en uzak olan alternatifi seçmektir (Tzeng ve Huang, 2011). Pozitif ideal çözüm, fayda kriterlerini en üst düzeye çıkaran ve maliyet kriterlerini en aza indiren bir çözümdür. Negatif ideal çözüm ise maliyet kriterlerini en üst düzeye çıkaran ve fayda kriterlerini en aza indiren bir çözümdür (Huang, 2008). Bu yöntem karar matrisinin oluşturulması ile başlayan 6 adımdan oluşmaktadır. Karar matrisin oluşturulması aşaması entropi yönteminin 
adımlarında anlatılmış olup, diğer adımlar aşağıdaki gibi sıralanmaktadır (Athawale ve Chakraborty, 2010; Tsaur, 2011; Özçelik ve Kandemir, 2015) :

Adım 2: Normalizasyon işlemi

Her bir alternatifin aldığı kriter değeri her bir alternatif değerinin karelerinin toplamının kareköküne bölünerek normalizasyon işlemi yapılmaktadır. Bunu için aşağıdaki denklem kullanılır.

$$
x_{i j}^{n}=\frac{x_{i j}}{\sqrt{\sum_{i=1}^{M M} x_{i j}^{2}}}
$$

Adım 3: Ağırlıklı ve normalleştirilmiş karar matrisinin oluşturulması

Normalizasyon işleminden sonra her bir kriter için ağırlık değeri $\left(w_{\mathrm{j}}\right)$ belirlenir. Ağırlık değeri belirlerken literatürde en çok kullanılan yöntem olan entropi yöntemi kullanılmıştır. Entropi yöntemi ile kriterlerin ağırlık değerleri belirlendikten sonra normalize işlemi uygulanmış olan veriler ile ağırlık değerleri çarpılır $\left(\mathrm{V}_{\mathrm{ij}}=\right.$ $\left.x_{i j}^{b} * w_{j}\right)$ ve $\mathrm{V}$ matrisi elde edilir.

$$
V=\left|\begin{array}{ccc}
x_{1}^{s} w_{1} & \ldots & x_{m}^{s} w_{1 m} \\
w & \ldots & \ldots \\
x_{m 1}^{s} W_{1} & \ldots & x_{m n}^{s} w_{m n}
\end{array}\right|
$$

Adım 4: Pozitif $\left(V^{+}\right)$ve negatif $\left(V^{-}\right)$ideal çözüm değerlerinin belirlenmesi

Ağırlıklı-normalleştirilmiş değerler kullanılarak pozitif ideal çözüm $\left(V^{+}\right)$ve negatif ideal çözüm $\left(V^{-}\right)$değerleri belirlenir. Pozitif ideal değerleri her bir kriter (sütun) değerlerinden en büyük değer seçilerek belirlenirken, negatif ideal çözüm değerleri her bir kriter değerlerinden en küçük değer seçilerek belirlenir.

$$
\begin{aligned}
& V^{+}=\left\{\left(\sum_{i}^{\max } v_{i j} / j \in J\right),\left(\sum_{i}^{\min } v_{i j} / j \in J^{v}\right) / i=1,2, \ldots . . N\right\} \\
& V^{-}=\left\{\left(\sum_{i}^{\min } v_{i j} / j \in J\right),\left(\sum_{i}^{\max } v_{i j} / j \in J^{v}\right) / i=1,2, \ldots N\right\}
\end{aligned}
$$

Denklem (5) ve (6)'da $l$ fayda (maksimizasyon) ve $l^{s}$ maliyet (minimizasyon) değerini ifade etmektedir.

Adım 5: Pozitif $\left(\mathrm{A}^{+}\right)$ve negatif $\left(\mathrm{A}^{-}\right)$ideal çözüme uzaklıkların hesaplanması

Denklem 7 ve 8 kullanılarak pozitif ve negatif ideal çözüme uzaklıklar hesaplanır. Hesaplama sırasında öklid uzaklıkları kullanılır.

$$
\begin{aligned}
& s^{+}=\left\{\sqrt{\sum\left(v_{i j}-v_{j}^{+}\right)^{2}}\right\}, \mathrm{i}=1,2 \ldots . \mathrm{N} \\
& s^{-}=\left\{\sqrt{\sum\left(v_{i j}-v_{j}^{-}\right)^{2}}\right\}, \mathrm{i}=1,2, \ldots . \mathrm{N}
\end{aligned}
$$

Adım 6: İdeal çözüme göreli yakınlığının $\left(C_{i j}^{*}\right)$ hesaplanması ve alternatiflerin sıralanması

Her bir alternatifin ideal çözüme göreceli yakınlığının $\left(C_{i}^{*}\right)$ hesaplanmasında pozitif ideal çözüme ve negatif ideal çözüme uzaklıklar kullanılır. Her bir alternatifin ideal çözüme göreceli yakınlığı denklem (9) kullanılarak hesaplanır. $\left(C_{i}^{*}\right)$ değeri 0 ile 1 arasında bir değer alır $\left(0 \leq C_{i}^{*} \leq 1\right)$. $C_{i}^{*}$ değerinin 0 'a yakın olması alternatifin pozitif ideal çözüme mutlak yakınlığını ve $C_{i ̂}^{*}$ değerinin 1'e yakın olması alternatifin negatif ideal çözüme mutlak yakınlığını gösterir. $C_{i}^{*}$ değeri büyük olan alternatif ilk sırada olacak şekilde alternatifler sıralanır.

$$
C_{i}^{*}=\frac{\Sigma_{1}^{-}}{s_{1}^{-}+s_{i}^{+}}
$$

\section{Bulgular}

\subsection{Entropi Yöntemi}

Kriterlerin ağırlık değerlerinin belirlenmesi ve işletmelerin finansal performanslarının değerlendirmesi için ilk olarak (6x11) boyutlu karar matrisi oluşturulmuştur. Oluş̧urulan karar matrisin satırlar kısmında alternatifler (işletmeler) ve sütunlar kısmında kriterler (finansal oranlar) yer almaktadır. 2015, 2016 ve 2017 yıllarının karar matrisi ise ekler kısmında verilmiş̧ir. 
Tablo 4. Karar matrisi (2014 y1lı)

\begin{tabular}{lccccccccccc}
\hline & L1 & L2 & M1 & M2 & M3 & F1 & F2 & K1 & K2 & K3 & N1 \\
\hline C & 1.359 & 0.056 & 0.675 & 0.480 & 0.253 & 5.696 & 1.848 & 0.021 & 0.121 & 0.039 & 0.776 \\
E & 1.825 & 1.222 & 0.932 & 0.073 & 0.005 & 28.312 & 1.922 & 0.015 & 0.436 & 0.030 & 0.937 \\
A & 1.789 & 0.382 & 0.834 & 0.199 & 0.635 & 4.791 & 0.796 & 0.035 & 0.170 & 0.028 & 0.807 \\
D & 1.825 & 0.981 & 0.791 & 0.264 & 0.452 & 3.885 & 0.811 & 0.027 & 0.106 & 0.022 & 0.937 \\
F & 1.227 & 0.106 & 0.520 & 0.923 & 0.754 & 1.321 & 0.634 & 0.049 & 0.065 & 0.031 & 0.824 \\
B & 1.274 & 1.274 & 0.328 & 2.053 & 0.867 & 1.595 & 1.073 & 0.109 & 0.174 & 0.117 & 0.598 \\
\hline
\end{tabular}

Kriterlerin ağırlık değerlerinin belirlenmesi için karar matrisinin oluşturulmasından sonra denklem (1) yardımıyla veriler normalize edilmiştir. Normalizasyon işlemi esnasında karar matrisindeki veriler kullanılmıştır. Daha sonra normalize veriler ile denklem (2) ve (3) kullanılarak her bir kritere ait sırasıyla entropi değeri ve ağırlık değeri elde edilmiştir. Entropi ve ağırlık değerleri Tablo 5 ve 6 ' da verilmiştir.

Tablo 5. Çalışmada kullanılan kriterlerin entropi değerleri

\begin{tabular}{cccccccccccc}
\hline & L1 & L2 & M1 & M2 & M3 & F1 & F2 & K1 & K2 & K3 & N1 \\
\hline $\mathbf{2 0 1 4}$ & 0.9917 & 0.8080 & 0.9726 & 0.7465 & 0.8623 & 0.6821 & 0.9488 & 0.8710 & 0.8919 & 0.8820 & 0.9943 \\
$\mathbf{2 0 1 5}$ & 0.9928 & 0.9127 & 0.9710 & 0.7196 & 0.9350 & 0.5900 & 0.9167 & 0.8549 & 0.9751 & 0.9102 & 0.9937 \\
$\mathbf{2 0 1 6}$ & 0.5225 & 0.3667 & 0.9880 & 0.8422 & 0.8352 & 0.5189 & 0.9424 & 0.9082 & 0.9002 & 0.8754 & 0.9960 \\
$\mathbf{2 0 1 7}$ & 0.9453 & 0.9340 & 0.9772 & 0.7335 & 0.8339 & 0.5214 & 0.9909 & 0.8303 & 0.8035 & 0.8345 & 0.9964 \\
\hline
\end{tabular}

Tablo 6. Çalıșmada kullanılan kriterlerin ağırlık değerleri

\begin{tabular}{cccccccccccc}
\hline & L1 & L2 & M1 & M2 & M3 & F1 & F2 & K1 & K2 & K3 & N1 \\
\hline $\mathbf{2 0 1 4}$ & 0.0062 & 0.1424 & 0.0203 & 0.1880 & 0.1021 & 0.2357 & 0.0380 & 0.0956 & 0.0801 & 0.0875 & 0.0042 \\
$\mathbf{2 0 1 5}$ & 0.0059 & 0.0711 & 0.0236 & 0.2283 & 0.0529 & 0.3338 & 0.0678 & 0.1181 & 0.0203 & 0.0731 & 0.0051 \\
$\mathbf{2 0 1 6}$ & 0.2072 & 0.2748 & 0.0052 & 0.0685 & 0.0715 & 0.2088 & 0.0250 & 0.0398 & 0.0433 & 0.0541 & 0.0017 \\
$\mathbf{2 0 1 7}$ & 0.0342 & 0.0413 & 0.0143 & 0.1667 & 0.1039 & 0.2993 & 0.0057 & 0.1061 & 0.1229 & 0.1035 & 0.0023 \\
\hline
\end{tabular}

Entropi yöntemine göre 2014, 2015 ve 2017 y1lı için en önemli kriter F1 (özsermaye devir hız1), 2016 yılı için en önemli kriter ise L2 (asit-test oran1) bulunmuştur. En önemsiz kriter ise 2014 -2017 y1lları için N1(maliyet/net satışlar) bulunmuştur.

\subsection{TOPSIS Yöntemi}

Artvin'deki orman işletmelerin finansal performans değerlendirilmesi ve sıralanması aşamasında da Entropi yöntemi ile kriterlerin ağırlıkların belirlenmesinde kullanılan karar matris (Tablo 5) kullanılmıştır. TOPSIS yönteminin uygulamasında 2014 yılı için tablolar elde edilmiştir. Diğer yılların sadece alternatiflerin $\mathrm{C}^{+}$ değerleri ve sıralama sonuçları tablo halinde verilmiştir.

$\mathrm{Bu}$ matristeki veriler kullanılarak her bir alternatifin aldığı kriter değeri her bir alternatif değerinin karelerinin toplamının kareköküne bölünerek normalizasyon işlemi yapılmıştır. Diğer bir deyişle veriler denklem (4) kullanılarak normalize edilmiştir. Normalize edilmiş verilerin oluşturduğu matris ise Tablo 7'de verilmiştir.

Tablo 7. Normalizasyon matrisi (2014 y1l1)

\begin{tabular}{lccccccccccc}
\hline & L1 & L2 & M1 & M2 & M3 & F1 & F2 & K1 & K2 & K3 & N1 \\
\hline C & 0.3528 & 0.0272 & 0.3884 & 0.2065 & 0.1794 & 0.1924 & 0.5858 & 0.1628 & 0.2292 & 0.2897 & 0.3858 \\
E & 0.4739 & 0.5936 & 0.5360 & 0.0313 & 0.0035 & 0.9564 & 0.6092 & 0.1178 & 0.8246 & 0.2180 & 0.4660 \\
A & 0.4644 & 0.1857 & 0.4795 & 0.0856 & 0.4500 & 0.1619 & 0.2522 & 0.2711 & 0.3211 & 0.2077 & 0.4011 \\
D & 0.4737 & 0.4763 & 0.4550 & 0.1134 & 0.3205 & 0.1312 & 0.2570 & 0.2094 & 0.2011 & 0.1635 & 0.4655 \\
F & 0.3187 & 0.0515 & 0.2990 & 0.3969 & 0.5342 & 0.0446 & 0.2010 & 0.3790 & 0.1238 & 0.2314 & 0.4097 \\
B & 0.3307 & 0.6188 & 0.1883 & 0.8824 & 0.6142 & 0.0539 & 0.3400 & 0.8359 & 0.3296 & 0.8632 & 0.2975 \\
\hline
\end{tabular}

Normalizasyon matrisindeki her bir alternatifteki her bir kriterin değeri ile entropi yöntemi elde edilmiş olan her bir kriterin ağırlık değerleri (Tablo 6'daki değerler) çarpılarak ağırlıklandırılmış normalizasyon matrisi elde edilmiştir ve sonuçlar Tablo 8'de verilmiştir. 
Tablo 8. Ağırlıklandırılmış normalizasyon matrisi (2014 yılı)

\begin{tabular}{lccccccccccc}
\hline & L1 & L2 & M1 & M2 & M3 & F1 & F2 & K1 & K2 & K3 & N1 \\
\hline C & 0.0022 & 0.0039 & 0.0079 & 0.0389 & 0.0183 & 0.0455 & 0.0223 & 0.0153 & 0.0184 & 0.0253 & 0.0016 \\
E & 0.0029 & 0.0845 & 0.0109 & 0.0059 & 0.0004 & 0.2254 & 0.0232 & 0.0113 & 0.0661 & 0.0191 & 0.0020 \\
A & 0.0029 & 0.0264 & 0.0097 & 0.0161 & 0.0459 & 0.0382 & 0.0096 & 0.0259 & 0.0257 & 0.0182 & 0.0017 \\
D & 0.0029 & 0.0678 & 0.0092 & 0.0213 & 0.0327 & 0.0310 & 0.0098 & 0.0200 & 0.0161 & 0.0143 & 0.0020 \\
F & 0.0020 & 0.0073 & 0.0061 & 0.0746 & 0.0545 & 0.0105 & 0.0076 & 0.0362 & 0.0099 & 0.0202 & 0.0017 \\
B & 0.0021 & 0.0881 & 0.0038 & 0.1659 & 0.0627 & 0.0127 & 0.0129 & 0.0799 & 0.0264 & 0.0755 & 0.0013 \\
\hline
\end{tabular}

Ağırlıklı normalizasyon (V) matrisi oluşturulduktan sonra V matrisi değerleri kullanılarak pozitif-ideal çözüm $\left(\mathrm{A}^{+}\right)$ve negatif-ideal çözüm $\left(\mathrm{A}^{-}\right)$değerleri elde edilmiştir. Pozitif-ideal çözüm $\left(\mathrm{A}^{+}\right)$değerleri her bir kriter (sütun) değerlerinden en büyük değer, negatif-ideal çözüm $\left(\mathrm{A}^{-}\right)$değerleri ise en küçük değer seçilerek belirlenmiştir. Elde edilen pozitif ve negatif ideal çözüm değerleri ise Tablo 9'da verilmiştir.

Tablo 9. Pozitif ve negatif ideal çözüm değerleri (2014 yılı)

\begin{tabular}{lccccccccccc}
\hline & L1 & L2 & M1 & M2 & M3 & F1 & F2 & K1 & K2 & K3 & N1 \\
\hline $\mathbf{A}^{+}$ & 0.0029 & 0.0881 & 0.0109 & 0.1659 & 0.0627 & 0.2254 & 0.0232 & 0.0799 & 0.0661 & 0.0755 & 0.0020 \\
$\mathbf{A}^{-}$ & 0.0020 & 0.0039 & 0.0038 & 0.0059 & 0.0004 & 0.0105 & 0.0076 & 0.0113 & 0.0099 & 0.0143 & 0.0013 \\
\hline
\end{tabular}

Daha sonra V matrisi değerleri ve pozitif-ideal çözüm ve negatif-ideal çözüm değerleri kullanılarak her bir alternatifin (satır) pozitif-ideal çözümden olan mesafesi $\left(\mathrm{S}^{+}\right)$ve negatif-ideal çözümden olan mesafesi $\left(\mathrm{S}^{-}\right)$ hesaplanmış olup, bunun için denklem (7) ve (8) kullanılmıştır. Hesaplanan $\mathrm{S}^{+}$ve $\mathrm{S}^{-}$değerleri aşağıdaki gibidir:

$$
\begin{aligned}
& S^{+}=(0.2579 ; 0.1933 ; 0.2638 ; 0.2646 ; 0.2636 ; 0.2167) \\
& S^{-}=(0.0555 ; 0.2370 ; 0.0630 ; 0.0770 ; 0.0912 ; 0.2129)
\end{aligned}
$$

Pozitif $\left(\mathrm{S}^{+}\right)$ve negatif $\left(\mathrm{S}^{-}\right)$ideal çözümden olan mesafeler hesaplandıktan sonra $\mathrm{S}^{+}$ve $\mathrm{S}^{-}$değerleri ve denklem (9) kullanılarak her bir alternatifin ideal çözüme göreceli yakınlık $\left(\mathrm{C}^{+}\right)$değerleri elde edilmiştir. Daha sonra $\mathrm{C}^{+}$ değeri büyük olan alternatif ilk sırada olacak şekilde alternatifler sıralanmıştır ve sıralama sonuçları Tablo 10'da verilmiştir.

Tablo 10. Alternatif $\mathrm{C}^{+}$değerleri ve sıralama sonuçları

\begin{tabular}{ccccccccc}
\hline & \multicolumn{2}{c}{$\mathbf{2 0 1 4}$} & \multicolumn{2}{c}{$\mathbf{2 0 1 5}$} & \multicolumn{2}{c}{$\mathbf{2 0 1 6}$} & \multicolumn{2}{c}{$\mathbf{2 0 1 7}$} \\
\hline C & $\mathbf{C}^{+}$ & Sıralama & $\mathbf{C}^{+}$ & Sıralama & $\mathbf{C}^{+}$ & Sıralama & C $^{+}$ & Sıralama $^{-}$ \\
E & 0.1771 & 6 & 0.1349 & 5 & 0.0656 & 6 & 0.2036 & 4 \\
A & 0.5508 & 1 & 0.6141 & 1 & 0.3875 & 2 & 0.6372 \\
D & 0.1928 & 5 & 0.1294 & 6 & 0.1388 & 3 & 0.1474 & 6 \\
F & 0.2254 & 4 & 0.1509 & 4 & 0.6199 & 1 & 0.2680 & 3 \\
B & 0.2570 & 3 & 0.3550 & 2 & 0.1240 & 4 & 0.3975 & 2 \\
\hline
\end{tabular}

Yapılan analiz sonucunda, 2014, 2015 ve 2017 yıllarında en iyi finansal performans sergileyen işletme "E"; 2016 yılında en iyi finansal performans sergileyen işletme "D"; 2014 ve 2016 yıllarında en kötü finansal performans sergileyen işletme "C"; 2015 ve 2017 yıllarında en kötü finansal performans sergileyen işletme "A" bulunmuştur.

\section{Sonuç ve Öneriler}

Orman ürünleri sektörü diğer sektörleri beslemesi, katma değer sağlayarak istihdam artışına katkı sağlaması, üretim büyüklüğü, ihracata yaptığı katkıdan dolayı Türkiye ekonomisinde önemli bir yere sahip olmaktadır. Çok kriterli karar verme yöntemlerinin orman ürünleri sektöründe kullanımı ile ilgili fazla bir çalışma da bulunmamaktadır.

Bu çalışmada Artvin'de faaliyet gösteren orman ürünleri işletmelerinin finansal performansları yıllara göre ayrı ayrı değerlendirilmiştir. İşletmelerin finansal performanslarının değerlendirilmesi için çok kriterli karar verme tekniklerinden biri olan Technique for Order Preference by Similarity to Ideal Solution (TOPSIS) yöntemi kullanılmıştır. Çalışmada kullanılan 11 finansal oran her yıl için ayrı ayrı hesaplanmıştır. Finansal oranların (kriterlerin) ağırlık değerleri Entropi yöntemi yardımı ile belirlenmiştir. Farklı ağırlıklandırma teknikleri olmasına rağmen daha objektif sonuçlar elde etmek için Entropi tekniği kullanılmıştır. TOPSIS yöntemi ile kriterlerin hepsini aynı anda değerlendirilir. Çünkü performans değerlendirirken tek bir kritere göre değil birden fazla kriterle değerlendirilmesi gerekmektedir. 
Entropi tekniğine göre 2014, 2015 ve 2017 yılı için en önemli kriter F1(özkaynak devir hızı), 2016 yllı için en önemli kriter L2(asit-test oranı) çıkmıştır. F1 kriteri 2016 yılı için ikinci önemli kriter, diğer yıllar için ikinci önemli kriter olarak M2 (finansman oranı) çıkmıştır. N1 (maliyet/satışlar) kriteri ise bütün yıllar için en önemsiz çıkmıştır. Bulgurcu (2013) tarafindan yapılan çalışmada da en önemli krtiterler borç özkaynak oranı, döner varlıkların devir hızı, duran varlıkların devir hızı olarak tespit edilmiştir. Dumanoğlu (2010) ve İslamoğlu ve ark. (2015) ise likidite oranlarının (cari oran, asit-test oranı ve nakit oranı) en yüksek önem derecesine sahip olduğunu söylemişlerdir.

TOPSIS yöntemine göre ise "E" işletmesi 2014, 2015 ve 2017 ylları için en iyi finansal performans sağlayan işletme iken, 2016 yllı için "E" işletmesi ikinci sıradadır. 2016 yılı için en iyi finansal performans sağlayan işletme ise " $D$ " işletmesidir. 2017 y1lında " $D$ " işletmesi finansal performans bakımından üçüncü sıradadır. 2014 yılı için ikinci en iyi finansal performans sağlayan işletme "B" işletmesi iken 2015 ve 2017 yllları için " $F$ " işletmesidir. "C" işletmesi 2014 ve 2016 yıllarında en kötü finansal performans sağlamıştır. 2015 ve 2017 yılları için en kötü finansal performans sağlayan işletme ise "A" işletmesi çıkmıştır. Finansal performans açısından "B" işletmesi yıllara göre düşüş göstermektedir. Genel olarak " $E$ " işletmesinin birinci sırada olmasının nedeni özkaynak devir hızının diğer işletmelerden fazla olmasıdır. "E" işletmesi finansal performans bakımından birinci sırada olsa da, cari oran ve asit-test oranı incelediğimizde 2016 ve 2017 yıllarında kısa vadeli borçları ödemede zorluk çektiği görülmektedir. "E" işletmesinin mali yapı oranlarını da incelediğimizde işletmenin yabanc1 kaynak baskısı altında olduğu görülmektedir. 2017 yılında "E" işletmesi aktifleri verimli kullanmamaktadır. İşletmenin karlılığı 2015 yılından sonra yükselişe geçmiştir. İşletmenin özkaynak karlılığı ise yıldan ylla dalgalanma göstermektedir. "E" işletmesi Artvin'de faaliyet gösteren diğer orman ürünleri işletmelerinden daha iyi finansal performans sergilese de, nakit, alacak, stok ve duran varlık politikalarını tekrar gözden geçirmeli, birim maliyetleri azaltmalı, özkaynaklara yönelmeli ve yabancı kaynak kullanımı azaltmalıdır.

Artvin'de faaliyet gösteren orman ürünleri işletmeler için yapılan bu çalışma işletme sahipleri ve yöneticilerine işletmelerinin finansal performansları hakkında bilgi vereblir ve yatırım yapacak kişilere ve kurumlara yatırım konusunda yardımcı olabilir. Rao (2000) TOPSIS yönteminin işletmelerin finansal bilgilerini gözden geçirmelerine ve en başarılı işletmelerin finansal durumlarını analiz etmelerine yardımcı olacağını savunmuştur. Diğer çok kriterli karar verme teknikleri ile finansal performans değerlendirmesi yapılabilir ve çıkan sonuçlar karşılaştırılabilir. Artvin'deki orman ürünleri işletmeleri ile İstanbul Borsa'da işlem gören orman ürünleri işletmeler karşılaştırılarak Artvin'deki orman ürünleri işletmelerinin durumu analiz edilebilir.

\section{Teşekkür}

Bilanço ve gelir tablosu temininde yaptıkları katkıdan dolayı çalışmada ismi geçen orman ürünleri işletmelerine teşekkür ederim.

\section{Kaynaklar}

1. Athawale VM, Chakraborty S (2010). A TOPSIS Method-Based Approach to Machine Tool Selection, Proceedings of the 2010 International Conference on Industrial Engineering and Operations Management Dhaka, Bangladesh.

2. Akyüz KC (2006). Competition of Forest Products Industry during to European Union Membership. ZKÜ Bartın Journal of Faculty of Forest, 8/9: 83-94.

3. Akyüz KC, Ersen N, Akyüz İ (2017). Borsa İstanbul'da Faaliyet Gösteren Kağıt ve Kağıt Ürünleri Sanayi Sektörü Firmalarının Performanslarının Gri İlişkisel Analiz Yöntemiyle Değerlendirilmesi. Akademik Sosyal Araştırmalar Dergisi, 51: 139-151.

4. Bulgurcu B (2013). Financial Performance Ranking of The Automotive Industry Firms in Turkey: Evidence From an Entropy-Weighted Technique. International Journal of Economics and Financial Issues, 3(4): 844-851.

5. Cantürk ŞF (2018). Furniture, Paper and Forest Products Sector: Export Figures Appraisal. (http://www.akib.org.tr/files/downloads/ArastirmaRaporlari/Agac/ocak-2018.PDF, Access date: 04/04/2018).

6. Chen J, Zihang Y, Chen Z, Nie Z (2015). Improving Assessment of Groundwater Sustainability with Analytic Hierarchy Process and Information Entropy Method: A Case Study of The Hohhot Plain, China. Environ Earth Sci, 73: 2353-2363.

7. Dai L, Wang J (2011). Evaluation of The Profitability of Power Listed Companies Based on Entropy Improved TOPSIS Method. Procedia Engineering. 15: 4728 - 4732. 
8. Deng H, Yeh CH, Willis RJ (2000). Inter-Company Comparison Using Modified TOPSIS with Objective Weights. Computers \& Operations Research, 27(10): 963-973.

9. Dumanoğlu S. (2010). İMKB’de İşlem Gören Çimento Şirketlerinin Mali Performansının TOPSIS Yöntemi ile Değerlendirilmesi. Marmara Üniversitesi İ.̇̇.B.F. Dergisi, XXIX(II): 323-339.

10. Ersen N, Akyüz İ, Bayram BÇ, Akyüz KC, Üçüncü T. (2018). Measurement of Financial Performance of Forest Products Industry: MULTIMOORA Method, II. Uluslararası Multidisipliner Çalışmaları Kongresi, 281-301, Adana.

11. Feng CM, Wang RT (2000). Performance Evaluation For Airlines Including The Consideration of Financial Ratios. Journal of Air Transport Management, 6(3): 133-142.

12. Huang J (2008). Combining Entropy Weight and TOPSIS Method For Information System Selection, Proceedings of the IEEE International Conference on Automation and Logistics Qingdao, 1965-1968, China.

13. Hwang CL, Lai YJ, Liu TY (1993). A New Approach For Multiple Objective Decision Making. Computers and Operational Research, 20: 889-899.

14. Hwang CL, Yoon K (1981). Multiple Attribute Decision Making: Methods and Applications, Springer, Heidelberg, Berlin.

15. İslamoğlu M, Apan M, Öztel A (2015). An Evaluation of The Financial Performance of REITS in Borsa Istanbul: A Case Study Using The Entropy-Based TOPSIS Method. International Journal of Financial Research, 6(2): 124-138.

16. Karademir F (2016). Finansal Analiz ve Kredi İşlemleri, Elma Yayınevi, Ankara.

17. Kayalı CA, Aktaş İ (2018). BİST’te Hisse Senetleri İşlem Gören Otomotiv Sektöründeki Firmaların TOPSIS Yöntemine Göre Performans Değerlemesi ve Analizi. Karabük Üniversitesi Sosyal Bilimler Enstitüsü Dergisi, 8(1): 43-59.

18. Kayıhan B (2017). Mali Performans Analizi: BIST Taş ve Toprağa Dayalı Sanayi Sektörü İşletmelerinde Bir Uygulama. The Journal of Academic Social Science, 46: 453-469.

19. Özçelik H, Kandemir B (2015). BIST'te İşlem Gören Turizm İşletmelerinin TOPSIS Yöntemi ile Finansal Performanslarının Değerlendirilmesi. Balıkesir University The Journal of Social Sciences Institute, 18 (33): 97-114.

20. Özerol H (2015). Finansçı Olmayanlar İçin Finans, Elma Yayınevi, Ankara.

21. Perçin S, Sönmez Ö (2018). Bütünleşik Entropi Ağırlık ve TOPSIS Yöntemleri Kullanılarak Türk Sigorta Şirketlerinin Performansının Ölçülmesi. International Journal of Economic and Administrative Studies, 18. EYİ Özel say1: 565-582.

22. Rao MP (2000). A Simple Method to Link Productivity to Profitability. Management Accounting Quarterly, 1(4): 12-17.

23. Savcı M (2013). Mali Tablolar Analizi, Ekin Yayınevi, Bursa.

24. Shannon CE, Weaver W (1949). The Mathematical Theory of Communication, The University of Illinois Press, Urbana, 1-117.

25. Shemshadi A, Shirazi H, Toreihi M, Tarokh MJ (2011). A Fuzzy VIKOR Method For Supplier Selection Based on Entropy Measure For Objective Weighting. Expert Systems with Applications, 38: 12160-12167.

26. Şahin D (2016). Analysis of Foreign Trade of Forest Based Sectors in Turkey. Journal of Bitlis Eren University Institute of Social Sciences, 5/Additional number: 181-196.

27. Şit A, Ekşi İH, Hacievliyagil N (2017). BIST’te Ana Metal Sanayi Endeksinde Faaliyet Gösteren İşletmelerin Finansal Performans Ölçümü: 201-2015 Dönemi. Süleyman Demirel Üniversitesi Vizyoner Dergisi, 8(17): 83-91.

28. Temür AS, İşler İ̇, Temür G (2017). Finansal Performansın TOPSIS Yöntemi ile Değerlendirilmesi: BIST Perakende Ticaret İşletmeleri Üzerine Bir Uygulama. Kesit Akademi Dergisi, 3(11): 712-729.

29. Tsaur RC (2011). Decision Risk Analysis For an Interval TOPSIS Method. Applied Mathematics and Computation, 218: 4295-4304.

30. Tzeng GH, Huang JJ (2011). Multiple Attribute Decision Making: Methods and Applications, CRC Press, Newyork, USA.

31. Urfalıŏlu F, Genç T (2013). Çok Kriterli Karar Verme Teknikleri ile Türkiye'nin Ekonomik Performansının Avrupa Birliği Üye Ülkeleri ile Karşılaştırılması. Marmara Üniversitesi İ.İ.B. Dergisi, XXXV(II): 329-360.

32. Üçüncü T, Akyüz KC, Akyüz İ, Bayram BÇ, Ersen N (2018). Evaluation of Financial Performance of Paper Companies Traded at BIST with TOPSIS Method. Kastamonu Üniversitesi Orman Fakültesi Dergisi, 18(1): 92-98.

33. Üçüncü T, Akyüz KC, Bayram BÇ, Ersen N (2017a). A TOPSIS-Based Performance Assessment Study in Wood Panel Industry, International Symposium on New Horizons in Forestry, 341, Isparta.

34. Üçüncü T, Üçüncü K, Akyüz KC, Bayram BÇ, Ersen N (2017b). TOPSIS Yöntemiyle Mobilya Endüstrisinde Kuruluş Yeri Seçimi: Batı Karadeniz Bölgesi Örneği. İleri Teknoloji Bilimleri Dergisi, 6(3): 435-443. 
35. Wang TC, Hsu JC (2004). Evaluation of The Business Operation-Performance of The Listing Companies By Applying TOPSIS Method, IEEE International Conference on Systems, Man and Cybernetics, 12861291.

36. Wang TC, Lee HD (2009). Developing a Fuzzy TOPSIS Approach Based on Subjective Weights and Objective Weights. Expert Systems with Applications, 36: 8980-8985.

37. Woo Lee PT, Wei Lin C, Ho Shin S (2012). A Comparative Study on Financial Positions of Shipping Companies in Taiwan and Korea Using Entropy and Grey Relation Analysis. Expert Systems with Applications, 39: 5649-5657.

38. Yılmaz BB, Konyar AM (2013). Financial Performance Evaluation of Publicly Held Lodging Companies Listed in Istanbul Stock Exchange with TOPSIS Method. European Journal of Scientific Research, 95(1): 143-151.

39. Yılmaz T, Kaygın E, Gerekan B (2016). Gıda Maddeleri Sanayii Sektöründe Faaliyet Gösteren İşletmelerin Finansal Performansının TOPSIS Yöntemi ile Ölçülmesi: BIST Örneği. Akademik Sosyal Araştırmalar Dergisi, 4(33): 609-623.

40. Yoon K (1987). A Reconciliation Among Discrete Compromise Situations. Journal of Operational Research Society, 38: 277-286. 
Ek 1. 2015 y1lının karar matrisi

\begin{tabular}{lccccccccccc}
\hline & L1 & L2 & M1 & M2 & M3 & F1 & F2 & K1 & K2 & K3 & N1 \\
\hline C & 1.168 & 0.215 & 0.823 & 0.216 & 0.223 & 5.750 & 1.021 & 0.020 & 0.118 & 0.021 & 0.715 \\
E & 1.488 & 0.968 & 0.936 & 0.068 & 0.206 & 35.991 & 2.294 & 0.004 & 0.146 & 0.009 & 0.933 \\
A & 1.139 & 0.520 & 0.868 & 0.152 & 0.797 & 3.746 & 0.495 & 0.038 & 0.142 & 0.019 & 0.772 \\
D & 1.400 & 1.044 & 0.786 & 0.273 & 0.531 & 4.242 & 0.910 & 0.031 & 0.130 & 0.028 & 0.943 \\
F & 1.796 & 0.321 & 0.372 & 1.689 & 0.528 & 1.041 & 0.654 & 0.048 & 0.050 & 0.032 & 0.848 \\
B & 1.260 & 1.245 & 0.438 & 1.285 & 0.800 & 1.193 & 0.671 & 0.094 & 0.112 & 0.063 & 0.608 \\
\hline
\end{tabular}

Ek 2. 2016 y1lı için karar matrisi

\begin{tabular}{llllcclccccc}
\hline & \multicolumn{1}{c}{ L1 } & \multicolumn{1}{c}{ L2 } & M1 & M2 & M3 & F1 & F2 & K1 & K2 & K3 & N1 \\
\hline C & 1.147 & 0.269 & 0.846 & 0.182 & 0.194 & 8.525 & 1.313 & 0.015 & 0.130 & 0.020 & 0.730 \\
E & 0.822 & 0.614 & 0.973 & 0.028 & 2.254 & 65.702 & 1.768 & 0.005 & 0.341 & 0.009 & 0.946 \\
A & 0.935 & 0.269 & 0.676 & 0.478 & 1.049 & 6.575 & 2.128 & 0.040 & 0.265 & 0.086 & 0.861 \\
D & 17.073 & 13.532 & 0.783 & 0.277 & 0.267 & 4.804 & 1.043 & 0.029 & 0.141 & 0.031 & 0.956 \\
F & 1.437 & 0.285 & 0.516 & 0.938 & 0.534 & 1.266 & 0.613 & 0.047 & 0.060 & 0.029 & 0.877 \\
B & 1.086 & 1.067 & 0.609 & 0.641 & 0.872 & 1.562 & 0.610 & 0.046 & 0.072 & 0.028 & 0.695 \\
\hline
\end{tabular}

Ek 3. 2017 y1lı için karar matrisi

\begin{tabular}{lccccccccccr}
\hline & L1 & L2 & M1 & M2 & M3 & F1 & F2 & K1 & K2 & K3 & N1 \\
\hline C & 1.112 & 0.320 & 0.855 & 0.169 & 0.342 & 6.735 & 0.975 & 0.018 & 0.119 & 0.017 & 0.665 \\
E & 0.859 & 0.389 & 0.977 & 0.024 & 2.477 & 51.147 & 1.185 & 0.006 & 0.307 & 0.007 & 0.929 \\
A & 2.756 & 1.086 & 0.685 & 0.459 & 0.678 & 2.030 & 0.639 & 0.009 & 0.018 & 0.006 & 0.832 \\
D & 1.558 & 1.002 & 0.783 & 0.278 & 0.520 & 4.143 & 0.901 & 0.036 & 0.148 & 0.032 & 0.951 \\
F & 2.296 & 0.374 & 0.360 & 1.781 & 0.273 & 1.493 & 0.956 & 0.052 & 0.077 & 0.049 & 0.918 \\
B & 0.929 & 0.929 & 0.619 & 0.616 & 1.115 & 2.806 & 1.069 & -0.007 & -0.021 & -0.008 & 0.870 \\
\hline
\end{tabular}

